\title{
Experimental Investigation on Use of Wheat Straw Ash and Bentonite in Self-Compacting Cementitious System
}

\author{
Rao Arsalan Khushnood, ${ }^{1,2}$ Syed Ali Rizwan, ${ }^{2}$ Shazim Ali Memon, \\ Jean-Marc Tulliani, ${ }^{4}$ and Giuseppe Andrea Ferro ${ }^{1}$ \\ ${ }^{1}$ Dipartimento di Ingegneria Strutturale, Edile e Geotecnica (DISEG), Politecnico di Torino, Corso Duca Degli Abruzzi 24, \\ 10129 Torino, Italy \\ ${ }^{2}$ Department of Structural Engineering, NUST Institute of Civil Engineering (NICE), National University of Sciences and Technology, \\ Sector H-12, 44000 Islamabad, Pakistan \\ ${ }^{3}$ Department of Civil Engineering, COMSATS Institute of Information Technology, University Road, 22066 Abbottabad, Pakistan \\ ${ }^{4}$ Dipartimento Scienza Applicata e Tecnologia (DISAT), Politecnico di Torino, Corso Duca Degli Abruzzi 24, 10129 Torino, Italy
}

Correspondence should be addressed to Rao Arsalan Khushnood; rao_nust@yahoo.com and Shazim Ali Memon; shazimalimemon@gmail.com

Received 2 October 2014; Accepted 13 November 2014; Published 17 December 2014

Academic Editor: Mohd Sapuan

Copyright (C) 2014 Rao Arsalan Khushnood et al. This is an open access article distributed under the Creative Commons Attribution License, which permits unrestricted use, distribution, and reproduction in any medium, provided the original work is properly cited.

In this research, we evaluated the feasibility of wheat straw ash and bentonite (raw and heated at $150^{\circ} \mathrm{C}$ for 8 hrs) as secondary raw materials in self-compacting paste (SCP). The fresh and hardened properties of SCP formulations including water and superplasticizer demand, flow behavior, compressive and flexural strength development, water absorption, and acid attack resistance were evaluated. Moreover, porosity, microstructural, and mineralogical investigations were also carried out on SCP formulations. Test results showed that the properties of SCP formulations in fresh state depend on the morphology of secondary raw materials. For heated bentonite and wheat straw ash formulations, the 28 days of compressive and flexural strength were higher or almost similar to reference SCP formulation. Among SCP formulations, wheat straw ash formulation was found to be more effective in consuming free lime and showed significant decrease in porosity with time, which in turn improved the resistance of this SCP formulation against water absorption and acid attack. Based on the test results, it can be concluded that the successful utilization of wheat straw ash and bentonite SCP formulations will offer durable and environmental friendly option to construction industry.

\section{Introduction}

Self-consolidating concrete (SCC) is by definition a concrete that completely fills the formwork under its own weight while maintaining homogeneity and without any need for consolidation. It deforms under its own weight as a fluid does and holds the particles of all sizes without letting them segregate into ingredients. High deformability and segregation resistance are the two primary properties of SCC. High deformation is achieved by using efficient superplasticizer and high segregation resistance is achieved by using either low water/powder ratio or moderate water/powder ratio with viscosity enhancing agent. Various pozzolanic and non pozzolanic materials such as lime stone powder [1, 2], fly ash [3], silica fume [4], metakaolin [5], rice husk ash [6], and bagasse ash [7], have been used by many researchers in SCC formulation. Some of them are presented here.

Bosiljkov [1] investigated the influence of nonpozzolanic fillers (finely ground limestone and crushed limestone dust) on the fresh and hardened properties of SCC mixes. Test results showed that finer and better-graded limestone dust significantly enhances the deformability of the paste. Moreover, it was found out that with high filler volume, the required SCC properties were achieved at lower water/(cement + filler) ratio. Rizwan and Bier [8] carried out investigation on blends of limestone powder and fly ash 
on the response of self-compacting mortars (SCM) in fresh and hardened states. It was found that SCM using blended raw materials improved the overall response than those using either of them. The durability of SCC prepared with metakaolin and silica fume in replacement mode was investigated by Hassan et al. [4]. According to the test results, highly durable SCC mixtures were obtained using high metakaolin content with an optimum replacement percentage of around 20. Furthermore, it was found out that the durability of SCC mixtures prepared with higher MK content was superior to SCC containing silica fume.

Several researchers have evaluated the feasibility of using wheat straw ash (WSA) and bentonite in normal concrete [9-11]. However, the data regarding utilization of WSA and bentonite in self-compacting paste (SCP), to the best of our knowledge, is scarce or nonexistent. This research was therefore carried out to evaluate the feasibility of WSA and bentonite self-compacting paste formulations. The SCP formulations were prepared with $10 \%$ replacement level. This replacement level was chosen because a smaller amount of secondary raw material (SRM) results in optimum efficiency and gives a large increase in strength while the use of large amount has a smaller effect [12]. The successful utilization in prevailing environment will offer multiple benefits including cost effective solution to construction industry and reduced environmental and health issues and would have positive impact on the durability of the system.

\section{Wheat Straw and Bentonite Potential-Global and Pakistan Statistics}

Wheat is one of the primary sources of food for 2.45 billion people [13]. In 2014, the annual global production of wheat was around 705 million tons, out of which $75 \%$ was produced by 18 countries while around 20\% was produced by EU-27 [14]. According to the statistical data [14], Pakistan is ranked at 7 with $3.5 \%$ share to the world wheat production. As per Pan and Sano [15], the average yield of straw is around 1.3$1.4 \mathrm{~kg}$ per kg of grain. This places the global estimate of wheat straw at around 534 million tons and for Pakistan this value is around 18.46 million tons. The current use of this abundant supply of wheat straw, as described by Zhang et al. [13], is limited to feeding stuff [16], pulp and paper [17], nanomaterials [18], bioethanol [19], fertilizer [20], and construction of mud houses. However, in some parts of the world and especially in underdeveloped and developing countries, wheat straw is burnt in open field causing environmental issues and health problems. Huge amount of ash, obtained after burning of wheat straw, probably has no use and getting rid of it is also a problem. This research therefore evaluates the feasibility of using WSA in SCP formulations.

As far as bentonite is concerned, the total world production of bentonite has increased from 13.3 million tons in 2004 [21] to 15.5 million tons in 2011 [22] while Pakistan's annual production has increased from 6,154 tons in 2004 [21] to 30,840 tons in 2011 [22]. Moreover, Pakistan has millions of tons of bentonite reserves [9]. This research therefore also evaluates the feasibility of using bentonite (raw and heated) in SCP formulations.

\section{Experimental Investigation}

3.1. Materials and Mix Proportion. Locally available Ordinary Portland Cement (OPC) grade 42.5R in conformity with ASTM C150 [23] was used. Bentonite clay was collected from Jehangira situated at $33^{\circ} 59^{\prime} 56^{\prime \prime}$ latitude and $72^{\circ} 12^{\prime} 47^{\prime \prime}$ longitude according to Survey of Pakistan topographic sheet $43 \mathrm{C} / 1$ [10] and it was studied in raw and heated conditions. Heat treatment was given at $150^{\circ} \mathrm{C}$ [9] for $8 \mathrm{hrs}$ and the clay was ground according to the procedure mentioned in [10]. The powder was then sieved through number 200 standard mesh and resulting sample was used for SCP formulations. WSA was obtained by burning wheat straw available in 1$5 \mathrm{~cm}$ length. The burning of wheat straw was carried out for 5 hrs in a temperature controlled electric furnace having smoke vent at the top. During the entire burning process, temperature was maintained at $670^{\circ} \mathrm{C}$ as reported to be quite effective to attain good pozzolanic properties [11]. For all SCP formulations, bentonite and WSA were used in replacement mode by $10 \%$ weight of cement. A third generation polycarboxylate ester based powder type superplasticizer Melflux 2651 was used to achieve flow level of $30 \pm$ $1 \mathrm{~cm}$ as measured by Hagerman's mini slump. The following specimen designations were used for SCP formulations.

\section{CEM represents reference SCP formulation. \\ C $+10 \%$ WSA represents SCP formulation with $10 \%$ wheat straw ash. \\ $\mathrm{C}+10 \% \mathrm{BN}(\mathrm{H})$ represents SCP formulation with $10 \%$ heated bentonite. \\ $\mathrm{C}+10 \% \mathrm{BN}(\mathrm{R})$ represents SCP formulation with $10 \%$ raw bentonite.}

3.2. Mixing Regime. Hobart Mixer (5 L capacity) was used for mixing SCP formulations. Various mixing regimes [24] are mentioned in the literature; however, after experimenting, the following was adopted. The constituents were manually mixed in dry state for 1-2 minutes followed by feeding into the bowl the dry mixture along with the requisite mixing water predicted by water demand test. A slow mixing ( $145 \mathrm{rpm}$ ) was done for 60 seconds followed by fast mixing $(285 \mathrm{rpm})$ for 120 seconds [25]. The total mixing time was 3 minutes (180 seconds) for all SCP formulations.

3.3. Testing of Specimens. The particle size, surface area, and surface morphology of powdered WSA and bentonite samples were determined by using Laser Granulometer (Coulter LS 230), Brunauer-Emmett-Teller (Finesorb-3010), and Environmental Scanning Electron Microscope (XL 30 ESEM FEG). For chemical composition, X-ray fluorescence (JSX-3100RII) technique was used. The physical properties and chemical composition results of powdered samples are representative of three samples.

The water demand and setting times of reference SCP as well as those containing 10\% SRM (in replacement mode) were determined by Vicat apparatus at $20 \pm 1^{\circ} \mathrm{C}$ and $20 \pm 5 \%$ relative humidity. The superplasticizer amount required for a target flow of $30 \pm 1 \mathrm{~cm}$ was obtained for all formulations 
using Hagerman's mini slump cone having dimensions of 60 $\times 70 \times 100 \mathrm{~mm}^{3}$. Moreover, the flow behavior of SCP systems was characterized by Hagerman's mini slump cone spread and by $\mathrm{V}$ funnel time. The details of the test can be found in [8]. It needs to be pointed out here that the properties of SCP in fresh state represent the average of three specimens.

The flexural and compressive strength tests were carried out as per ASTM C 348 [26] and ASTM C 349 [27], respectively. Flexural strength of SCP formulation is the average of three $40 \times 40 \times 160 \mathrm{~mm}^{3}$ specimens while the compressive strength test was done on broken halves after flexural tests and strength represents the average of six specimens. For water absorption, ASTM C 642-04 [28] was followed while for acid attack test procedure mentioned by Rawal [29] was adopted. Three samples each were tested to determine the water absorption and acid attack test.

The porosity, microstructure, and mineralogical phases of SCP formulations were investigated using mercury intrusion porosimetry (MIP), scanning electron microscopy (SEM), and X-ray diffraction (XRD) at the age of 1 and 7 days. For SEM and MIP, two small pieces (approx. $1 \times 1 \mathrm{~cm}^{2}$ ) extracted from compression test were immediately immersed in acetone to stop further hydration in the surface zone and cleaned from free particles produced during fracture in an ultrasonic bath. The specimens were then submerged in isopropanol to remove traces of acetone left in the small pieces [30]. For SEM observations, the specimens were further treated for preparations normally performed including vacuum drying and gold coating while for MIP the samples were dried in oven at $105^{\circ} \mathrm{C}$ for $24 \mathrm{hrs}$ before testing. Moreover, for MIP, the contact angle of $140^{\circ}$ was selected. For XRD, two to three small pieces obtained from compressive tests were ground and the powdered samples were used for obtaining XRD diffractograms in the $5-70^{\circ} 2 \theta$ range.

\section{Results and Discussions}

\subsection{Characterization of Powdered Samples}

4.1.1. Physical Properties and Chemical Composition of Powders. The physical properties and chemical composition of powders are shown in Table 1 . The average particle size of bentonite is around one-fifth of the average cement particle size. Thus, it has comparatively large surface area. It can be seen that heat treatment is effective in reducing the moisture content of bentonite. It is believed that the loss of moisture might have increased the internal porosity of bentonite and thus resulted in increased surface area. Metha and Monteiro [31] described that heat treatment can improve the reactivity of natural pozzolans in cement paste and resultantly enhance certain properties of concrete. It is worth mentioning here that both the raw and heated bentonite meet the requirements of chemical composition of natural pozzolan as laid down in ASTM C 618-01 [32].

The chemical composition of WSA shows $\mathrm{SiO}_{2}$ and $\mathrm{K}_{2} \mathrm{O}$ as major constituents. According to Biricik et al. [11, 33], the chemical composition of WSA depends upon number of factors such as type of soil for growing wheat plant, the type of fertilizers used, environment, burning temperature, burning volume, and duration of burning. Visvesvaraya [34] pointed out that $\mathrm{SiO}_{2}$ content in WSA is dependent on soil and environmental conditions existed during development of wheat crop.

\subsubsection{Surface Morphology by Scanning Electron Microscopy} (SEM) and Mineralogical Composition by XRD Analysis. The size, shape, and texture of SRMs are important parameters to understand the response of SCP formulations. The micrographs of bentonite (raw and heated) and WSA are presented in Figure 1. Bentonite particles show layered structure which attracts and binds water molecules to its vast inner and outer surface area. The layered structure would also require a higher dosage of superplasticizer to overcome internal friction during flow. It can be seen that particles of raw bentonite show agglomeration due to the presence of internal moisture, whereas heated bentonite particles, in general, are separated. It can also be seen that the average particle size of bentonite clay ranges from 3 to $5 \mu \mathrm{m}$, which confirms the value given in Table 1 by laser technique. As far as the micrographs of WSA are concerned, the shape of the particles varies from angular to flat and elongated while the texture appears to be rough and abrasive. The micrograph also shows that the particles contain surface pits. All these, in turn, would increase the water demand of the SCP system to attain consistency.

The XRD of bentonite (raw and heated) and WSA is given in Figure 2. The heated and raw bentonites are composed of quartz, illite, montmorillonite, and clinochlore. Moreover, the heated bentonite seems to be relatively less crystalline than the corresponding raw form. As far as WSA sample is concerned, it possesses a large amorphous portion accompanied by minor traces of quartz and cristobalite. Furthermore, traces of kyanite were also found.

\subsection{Fresh and Hardened Properties of SCP Formulations}

4.2.1. Water Demand, Superplasticizer Demand, and Setting Time. The water and superplasticizer demands as well as setting times of SCP formulations for a target flow of $30 \pm 1 \mathrm{~cm}$ [25] are presented in Table 2. In comparison to CEM, both bentonite and WSA SCP formulations showed higher water and superplasticizer demand. For bentonite, the higher water and superplasticizer demand are due to the larger surface area arising from smaller particle size and layered structure which attracts and binds water molecules. In addition, in comparison to raw bentonite, heated bentonite showed higher water and superplasticizer demand. During thermal treatment, internal moisture from bentonite was extracted resulting in larger surface area and hence increased water and superplasticizer demand. Also, the results reported are in line with the available literature on bentonite used in normal cement concrete $[9,35]$. As far as WSA is concerned, the increase in water demand with respect to CEM is due to particle shape (angular to flat and elongated), texture (rough and abrasive), and larger surface area. For autoclaved normal cement mortar prepared with WSA, Al-Akhras and Abu-Alfoul [36] reported decrease in flow table values with increasing WSA replacement by weight of cement. Thus, 
TABLE 1: Physical and chemical properties of powders.

\begin{tabular}{|c|c|c|c|c|}
\hline Parameters & Cement (42.5R) & WSA & Bentonite $(\mathrm{H})$ & Bentonite (R) \\
\hline \multicolumn{5}{|c|}{ Physical properties } \\
\hline Mean particle size $(\mu \mathrm{m})$ & 22.00 & 12.30 & 4.32 & 4.75 \\
\hline Surface area $\left(\mathrm{cm}^{2} / \mathrm{g}\right)$ & 1,650 & 3,200 & 4,800 & 2,535 \\
\hline Specific gravity & 3.10 & 2.30 & 2.79 & 2.82 \\
\hline Moisture content (\%) & 2.90 & - & 0.05 & 3.20 \\
\hline \multicolumn{5}{|c|}{ Chemical analysis (\%) } \\
\hline $\mathrm{SiO}_{2}$ & 17.15 & 73.95 & 53.96 & 49.38 \\
\hline $\mathrm{TiO}_{2}$ & 0.32 & 1.92 & 0.93 & 1.85 \\
\hline $\mathrm{Al}_{2} \mathrm{O}_{3}$ & 5.60 & 0.91 & 20.27 & 17.54 \\
\hline $\mathrm{Fe}_{2} \mathrm{O}_{3}$ & 3.21 & 1.15 & 8.92 & 10.24 \\
\hline $\mathrm{MgO}$ & 1.44 & 1.83 & 4.02 & 3.80 \\
\hline $\mathrm{CaO}$ & 64.09 & 5.21 & 7.05 & 9.54 \\
\hline $\mathrm{K}_{2} \mathrm{O}$ & 1.19 & 11.51 & 3.93 & 4.83 \\
\hline \multicolumn{5}{|c|}{ Strength activity index (SAI) } \\
\hline${ }^{*} 7$ days & 100 & 96 & 94 & 77.26 \\
\hline${ }^{*} 28$ days & 100 & 104 & 99 & 85.18 \\
\hline
\end{tabular}

${ }^{*}$ SAI $\geq 75 \%$ of CEM (ASTM C618).

suggesting increase in the water demand of WSA mixes. It will be pertinent to mention here that SCM formulations using fly ash require less water and superplasticizer demand for a specific target flow. The lesser water and superplasticizer demand of fly ash formulations are due to their spherical shaped particles, which during flow roll over one another, reducing the internal friction $[37,38]$. However, for specific target flow, SCM/SCC formulations prepared with limestone powder (LSP) and metakaolin (MK) require more water and superplasticizer $[4,5,8,25]$. The higher demand for LSP is due to their irregular, rough, and patchy particle characteristics while for MK, the layered structure provides sites for internal friction during flow. The results of setting time presented in Table 2 show increase in the setting time of SCP formulations with addition of WSA and bentonite. The increase in the setting time of SCP formulations varies according to the individual characteristics of each SRM used.

4.2.2. Flow. After establishing the water demand, superplasticizer demand, and the setting times, the next parameter investigated for SCP formulations was flowability. The results of Hagerman's mini slump cone time for a spread of $25 \mathrm{~cm}$ $(\mathrm{T} 25 \mathrm{~cm})$ and $\mathrm{V}$ funnel time of various formulations are shown in Figure 3. In T25 cm cone flow time, mostly internal friction has to be overcome during unconfined flow of selfcompacting paste while in $\mathrm{V}$ funnel time, both internal and external frictions (between self-compacting paste and gradually reducing funnel section) are present which increase the overall friction and thus the flow time [8]. Increase in $\mathrm{T} 25 \mathrm{~cm}$ and $\mathrm{V}$ funnel time of SCP formulations containing bentonite and WSA indicate higher friction offered during flow. For the case of bentonite, friction was offered by the layered structure while for WSA, it is angular to flat and elongated shape, rough and abrasive texture and small surface pits were possible sites providing friction. In addition, the presence of internal free moisture in raw bentonite and its comparatively lesser surface area than "heated" bentonite (Table 1) indicates that more effective water is available in the system to help the flow. This makes the former SCP formulation less viscous than the latter. In summary, the flow of SCP formulation depends heavily on surface morphology and its internal porosity in addition to other influencing factors like mixing regime, sequence of admixtures addition, and water/superplasticizer contents.

4.2.3. Strength Activity Index (SAI). As per ASTM C618, SAI at 7 and 28 days should be $75 \%$ of the reference cement mix. SAI results presented in Table 1 show that all the specimens meet the requirements of ASTM C618 [32]. The mixes show higher rate of reactivity at 28 days than at 7 days suggesting increase in the reactivity rate. It can thus be inferred that OPC hydration and pozzolanic reaction have contributed to higher strength development rate of the SCP formulations. Mirza et al. [9] found out that Karak bentonite heated at $150^{\circ} \mathrm{C}$ for $3 \mathrm{hrs}$ had higher SAI than control and all other heated bentonites $\left(250^{\circ} \mathrm{C}, 500^{\circ} \mathrm{C}, 750^{\circ} \mathrm{C}\right.$, and $\left.950^{\circ} \mathrm{C}\right)$.

4.2.4. Compressive and Flexural Strength. The compressive and flexural strength results are shown in Figure 4. Up to the age of 7 days, the CEM SCP formulation showed higher compressive and flexural strength than SCP formulations containing WSA and bentonite. According to the available literature [31, 39], the strength gain in mixes containing pozzolan is generally slow at early ages. However, at 28 days, the SCP formulations with WSA and heated bentonite showed higher or almost similar compressive and flexural strength than CEM. The increase in strength can be attributed to pozzolanic reaction that takes place at a slower rate than the hydration of cement, better pore refinement effect, filler effect, and SRM's particle characterization. It is reported [8] that margin of strength increase is dependent upon the degree of pozzolanic activity of the SRM used. 


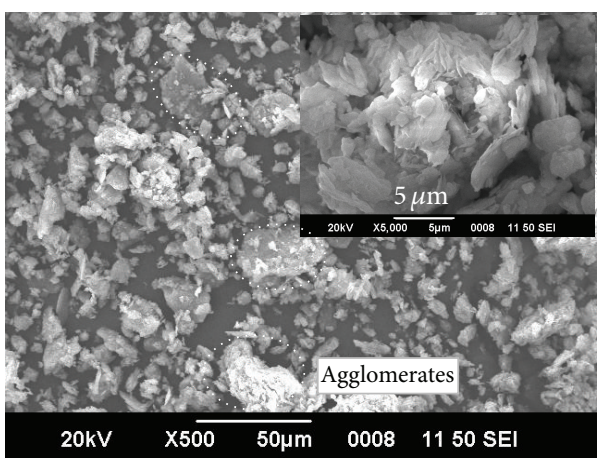

(a)

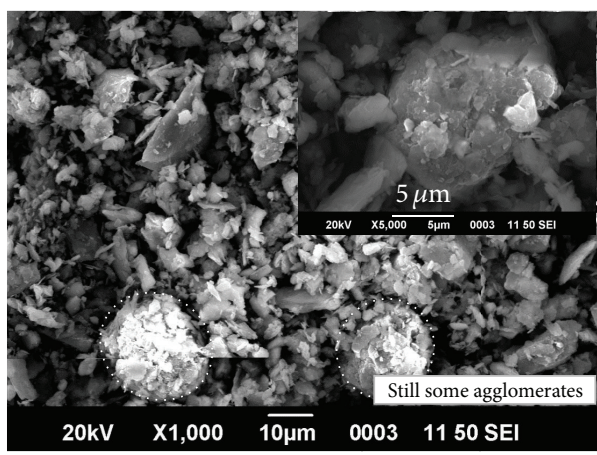

(c)

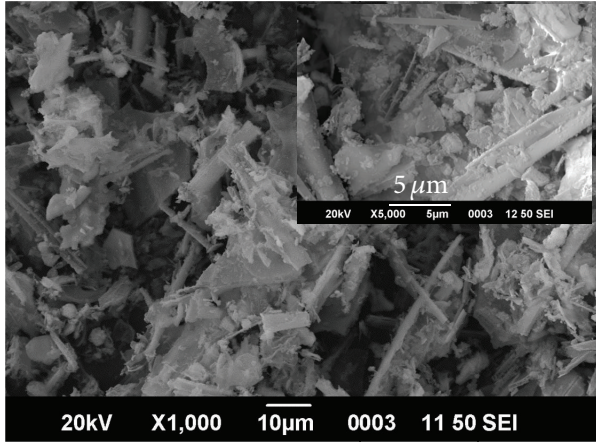

(e)

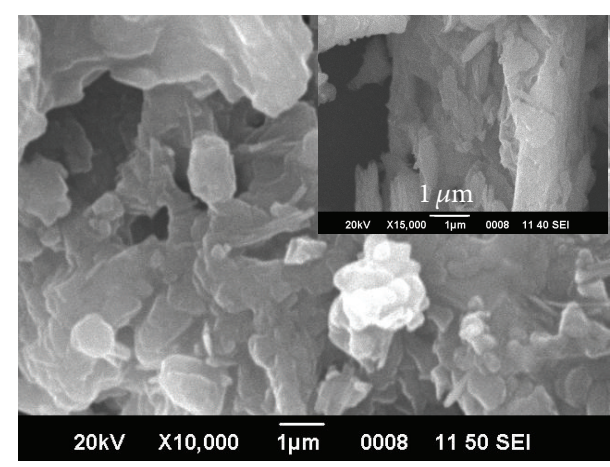

(b)

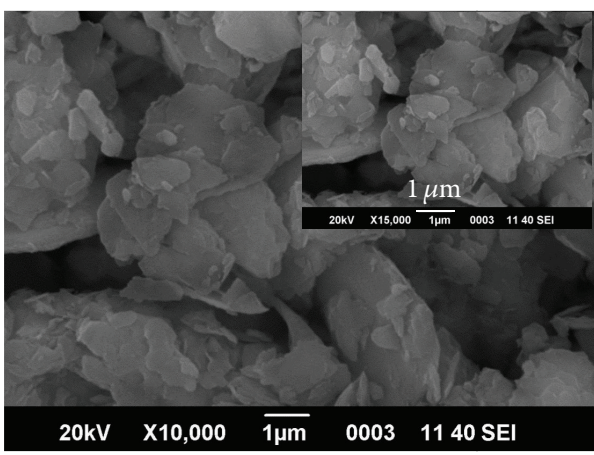

(d)

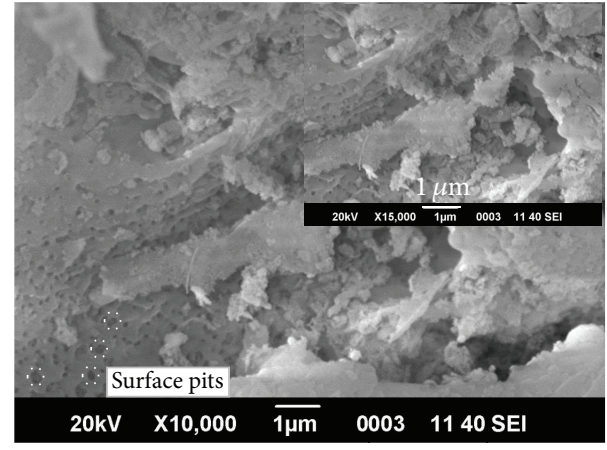

(f)

FIGURE 1: Micrographs of $(a, b)$ raw bentonite; $(c, d)$ heated bentonite; and $(e, f)$ WSA samples.

TABLE 2: Water demand, superplasticizer demand, and setting time of SCP formulations.

\begin{tabular}{lcccc}
\hline Formulation & \multirow{2}{*}{ Water demand (mass\% of cement) } & Superplasticizer demand (mass\% of cement) & $\begin{array}{c}\text { Setting time (min) } \\
\text { Initial }\end{array}$ & Final \\
\hline CEM & 28 & 0.146 & 310 \\
C $+10 \%$ WSA & 36 & 0.260 & 365 \\
C $+10 \%$ BN (H) & 33 & 0.320 & 225 \\
C $+10 \%$ BN (R) & 32 & 0.270 & 260 \\
\hline
\end{tabular}

4.2.5. Water Absorption. Water absorption results are presented in Figure 5. In comparison to CEM, SCP formulations containing WSA and bentonite showed decreased water absorption. It is due to the fact that the reaction between these pozzolans and calcium hydroxide from hydrated cement paste is lime consuming. In addition, it would be shown later that these pozzolans are effective in reducing the porosity of the system which, in turn, improves the durability of the system.

4.2.6. Resistance to Acid Attack. Resistance against acid attack of SCP formulations, with and without SRM, was measured in terms of percentage reduction in weight and strength after immersing the samples in 5 percent hydrochloric acid and 


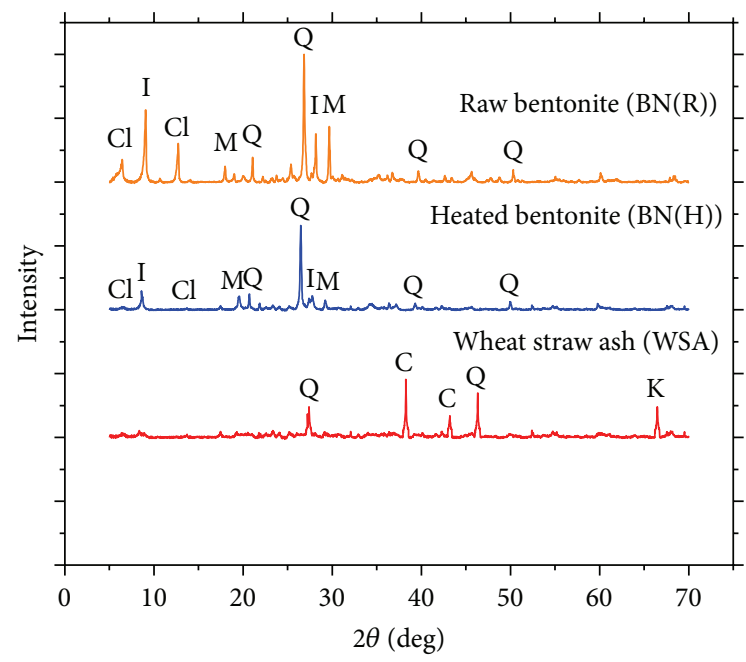

C: cristobalite; $\mathrm{SiO}_{2}$, syn.; tetragonal

Cl: clinochlore; $\mathrm{Mg}_{3.75} \mathrm{Fe}_{1.25}^{2+} \mathrm{Si}_{3} \mathrm{Al}_{2} \mathrm{O}_{10}(\mathrm{OH})_{8}$, syn.; monocline

I: illite; $\mathrm{K}_{0.6}\left(\mathrm{H}_{3} \mathrm{O}\right)_{0.4} \mathrm{Al}_{1.3} \mathrm{Mg}_{0.3} \mathrm{Fe}_{0.1}^{2+} \mathrm{Si}_{3.5} \mathrm{O}_{10}(\mathrm{OH})_{2} \cdot\left(\mathrm{H}_{2} \mathrm{O}\right)$, syn.; monocline

K: kyanite; $\mathrm{Al}_{2} \mathrm{SiO}_{5}$, syn.; triclinic

Q: quartz; $\mathrm{SiO}_{2}$, syn.; hexagonal

M: montmorillonite; $\mathrm{Na}_{0.2} \mathrm{Ca}_{0.1} \mathrm{Al}_{2} \mathrm{Si}_{4} \mathrm{O}_{10}(\mathrm{OH})_{2}\left(\mathrm{H}_{2} \mathrm{O}\right)_{10}$, syn.; monocline

FIgURE 2: XRD of powdered WSA and bentonite (heated and raw) samples.

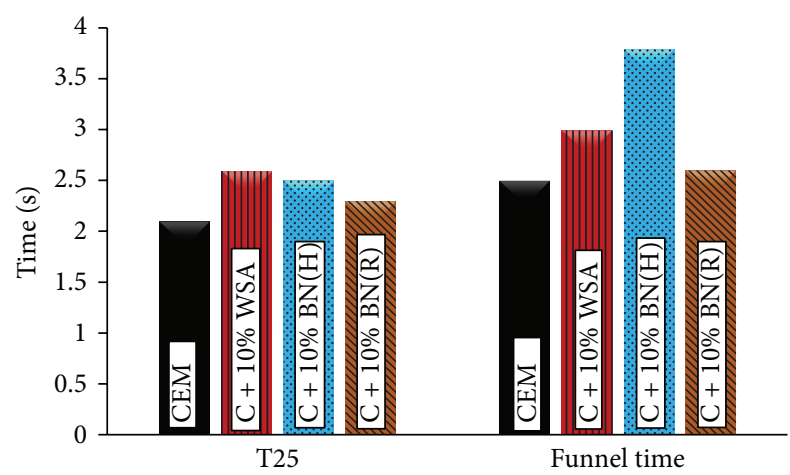

Figure 3: Flowability (T25 cm time and V funnel time) of SCP formulations.

5 percent sulfuric acid solutions for 14 and 28 days. The results are presented in Figure 6. The weight loss observed in the SCP formulations was due to the loss of cohesiveness of the cement hydration products [31]. It can be seen that the amount of weight loss was maximum for CEM in both of the acid solutions. The poor performance of CEM against acid attack is due to the fact that it releases considerable portion of free calcium hydroxide that reacts with the acid and a soft and mushy mass is left behind. For SCP formulations containing pozzolans, the free calcium hydroxide reacts with silica present in the mix to form secondary silica gel and thus reduces the amount of free calcium hydroxide. This, in turn, made the SCP formulations more durable. In addition, the lower loss in WSA mix was due to the relatively high content

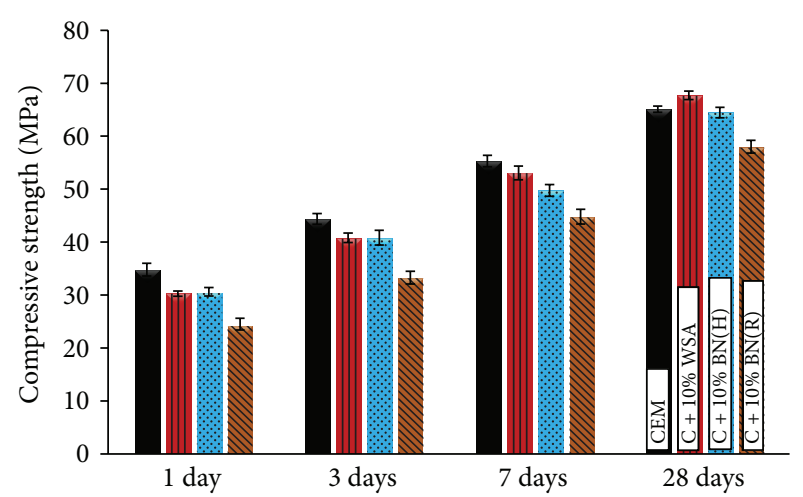

(a)

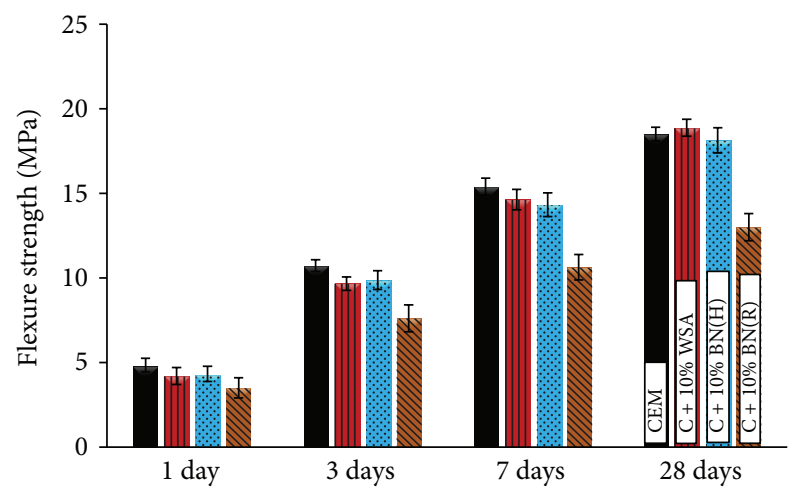

(b)

FIGURE 4: Variation in (a) compressive strength; (b) flexure strength of SCP formulations.

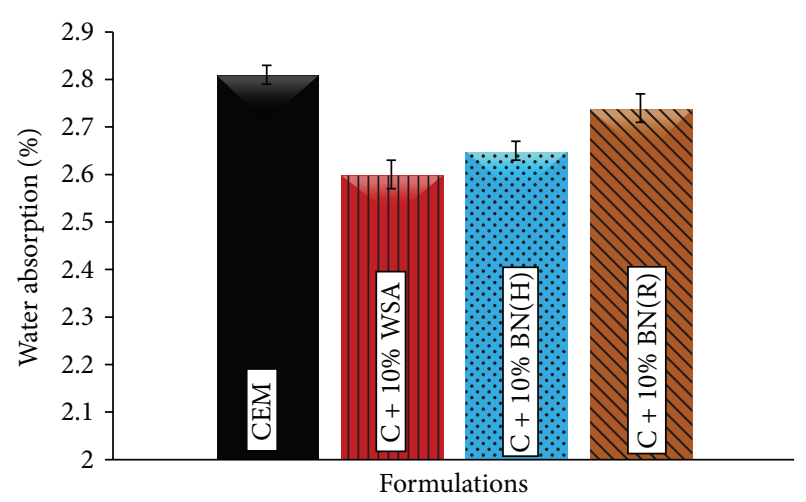

FIGURE 5: Water absorption of SCP formulations at 28 days.

of silica present in the mix for reaction with free calcium hydroxide and thereby making it more durable. It is worth mentioning that the amount of secondary C-S-H gel and subsequent reduction in free calcium hydroxide is dependent on the percentage of pozzolan in the mix. It can also be seen that more deterioration was caused by sulfuric acid than by hydrochloric acid. It is due to the fact that in case of sulfuric acid, a product called calcium sulfoaluminate hydrate also known as ettringite $\left[\mathrm{Ca}_{6} \mathrm{Al}_{2}\left(\mathrm{SO}_{4}\right)_{3}(\mathrm{OH})_{12} \cdot 26 \mathrm{H}_{2} \mathrm{O}\right]$ is formed, which expands and hence causes disruption of the set cement 


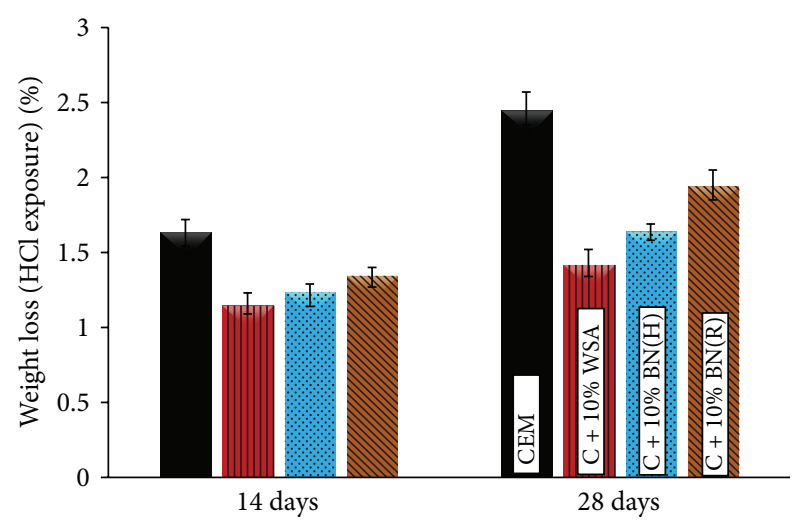

(a)

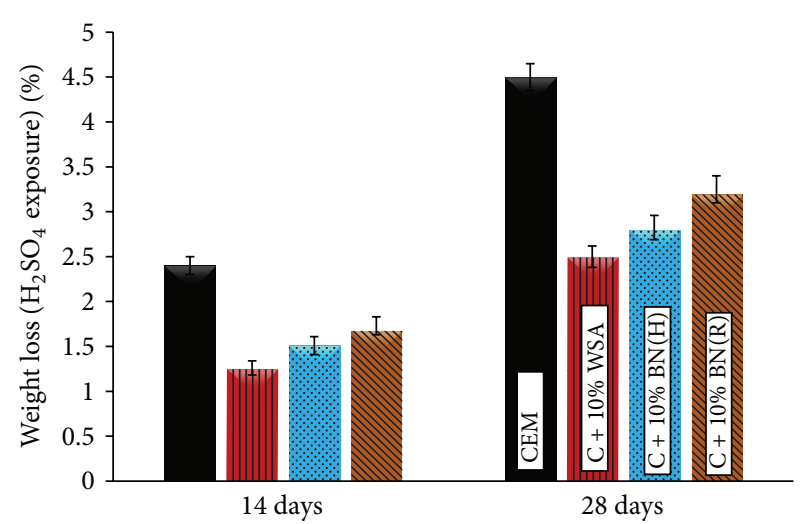

(b)

FIgURE 6: Effect of (a) $\mathrm{HCl}$; (b) $\mathrm{H}_{2} \mathrm{SO}_{4}$ on the weight loss of SCP formulations.

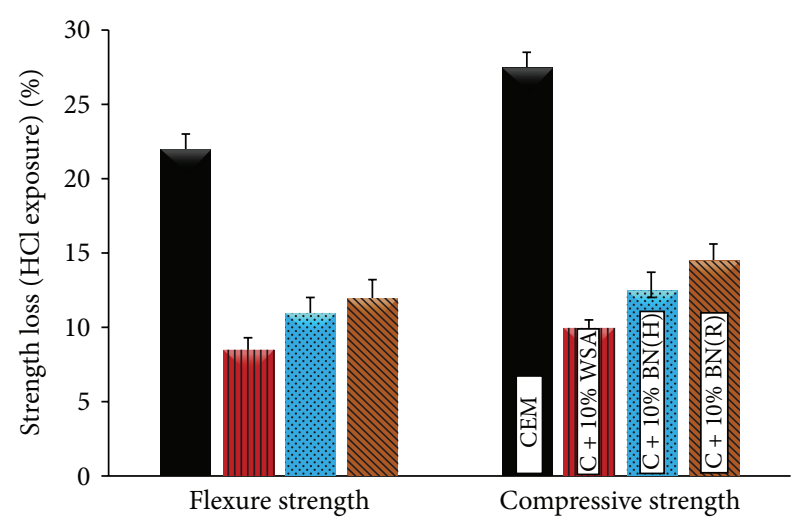

(a)

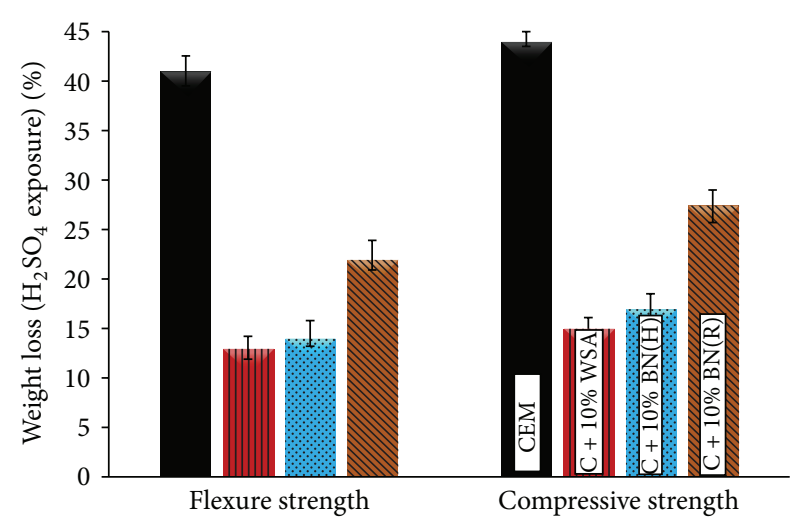

(b)

FIgURE 7: Effect of (a) $\mathrm{HCl}$; (b) $\mathrm{H}_{2} \mathrm{SO}_{4}$ on the strength loss of SCP formulations at 28 days.

paste [31], whereas no such product is formed in case of hydrochloric acid.

The results of compressive and flexure strength after exposure to $\mathrm{HCl}$ and $\mathrm{H}_{2} \mathrm{SO}_{4}$ are presented in Figure 7. CEM SCP formulation showed maximum strength loss. For $\mathrm{HCl}$ immersion, the loss in compressive and flexure strength was up to 21 and $28 \%$ while for $\mathrm{H}_{2} \mathrm{SO}_{4}$ immersion, the loss was up to 41 and $44 \%$, respectively. It can also be seen that WSA SCP formulation showed better performance. It would be shown later that the WSA SCP formulation was more effective in consuming free lime. Moreover, the improved performance of WSA SCP formulation was due to lowest porosity and average pore radius as determined by MIP. Based on the test results, it can be deduced that these SCP formulations can be used in acidic environment such as chemical industries, sewer pipes, foundations in ground waters containing high concentration of sulfates, and near sea water.

4.2.7. Scanning Electron Microscopy and Energy Dispersive XRay Spectroscopy of SCP Formulations. The micrographs of SCP formulations at the age of 1 and 7 days along with oxide composition extracted from EDX are displayed in Figure 8 and Table 3. All formulations showed the growth of ettringite in the form of needle-shaped crystals, hexagonal-prismatic crystals of calcium hydroxide and calcium silicate hydrate (C-S-H). The oxide analysis of cement paste prepared with WSA and bentonite showed reduction in the content of $\mathrm{CaO}$, thus testifying the efficiency of these pozzolans in reducing calcium hydroxide and transforming it into secondary C$\mathrm{S}-\mathrm{H}$ gel. It can also be seen that WSA is more effective in consuming $\mathrm{CaO}$ and thereby producing SCP formulation with improved mechanical properties and durable system. However, it should be noted here that for cementitious systems, the analysis appeared to be of just qualitative nature and definite quantitative results should not be expected due to large point to point variation in cement based materials.

4.2.8. Mercury Intrusion Porosimetry (MIP) of SCP Formulations. The porosity and pore size distribution were measured using MIP. The results are reported in Table 4. The results clearly indicate decrease in porosity and average pore radius with age. A significant decrease in porosity and average 


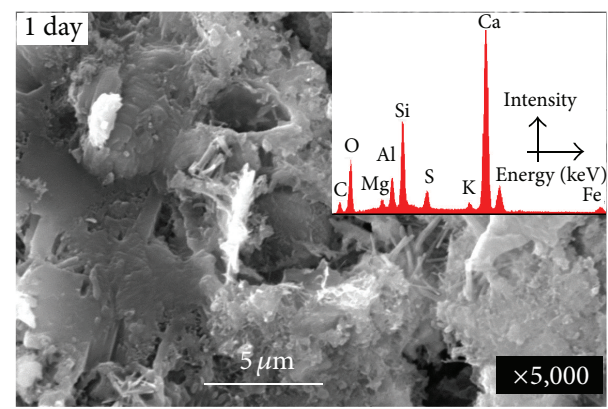

(a)

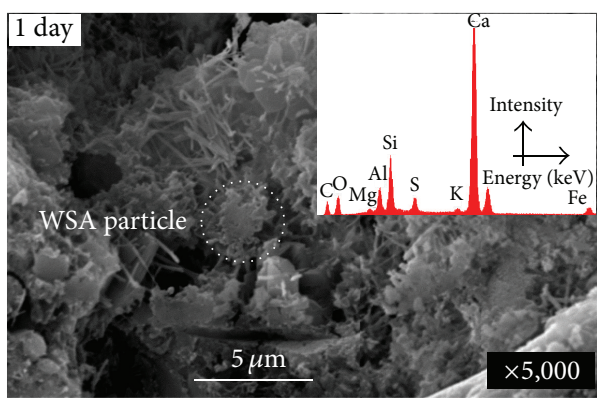

(c)

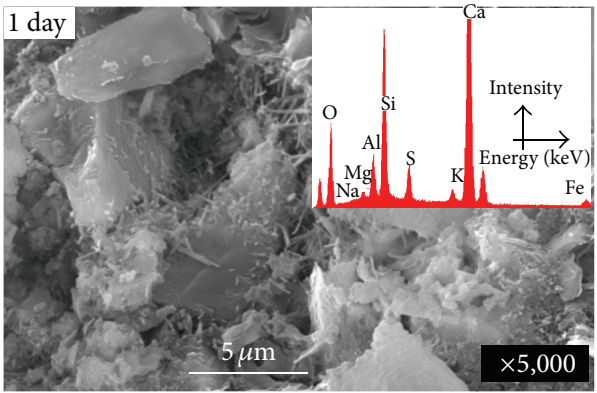

(e)

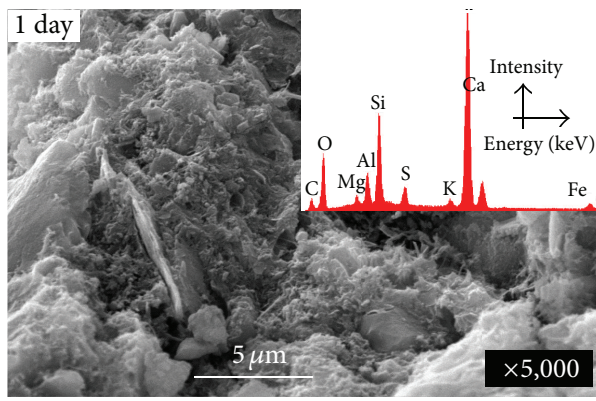

(g)

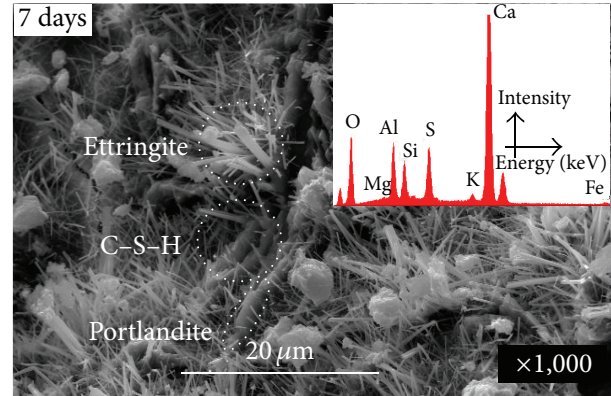

(b)

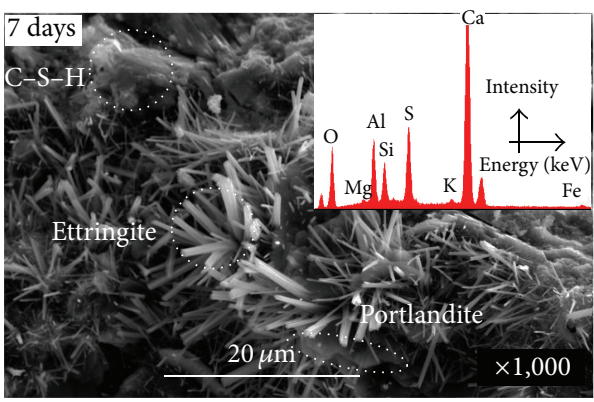

(d)

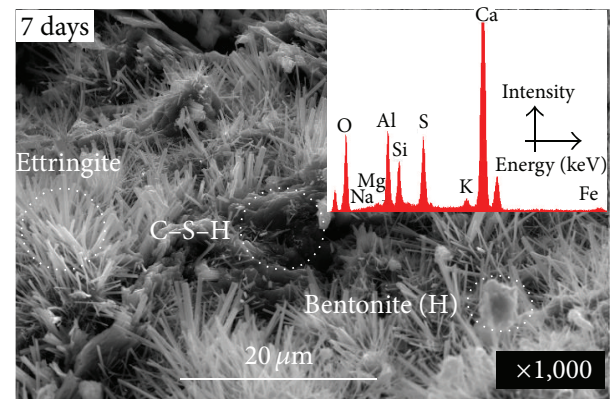

(f)

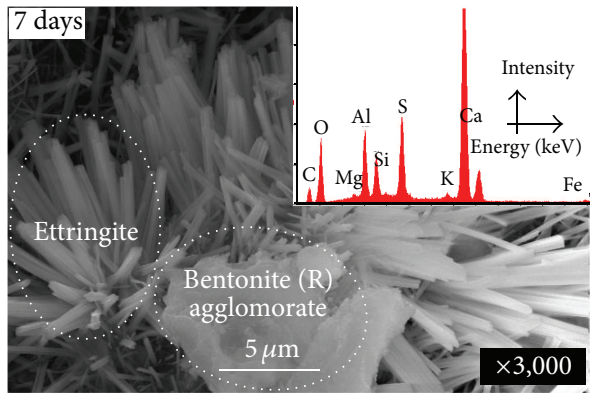

(h)

FIGURE 8: Micrographs of hydration products along with EDAX of (a, b) CEM; (c, d) C + 10\% WSA; (e, f) C + 10\% BN(H); and (g, h) C + $10 \% \mathrm{BN}(\mathrm{R})$ at 1 and 7 days.

pore radius was observed by the addition of pozzolans as compared to reference SCP formulation. This is one of the reasons contributing to better mechanical and durability performance of these pozzolans SCP formulations. Among SCP formulations containing pozzolan, WSA formulation showed lowest porosity and average pore radius at the age of 7 days. This explains why WSA SCP formulation showed better mechanical and durability performance among all other SCP formulations.

4.3. XRD Analysis of SCP Formulations. The mineralogical analysis by XRD in the $2 \theta$ range from 5 to $70^{\circ}$ was carried out to detect changes in the hydration products due to the presence of WSA, raw and heated bentonites at the age of 


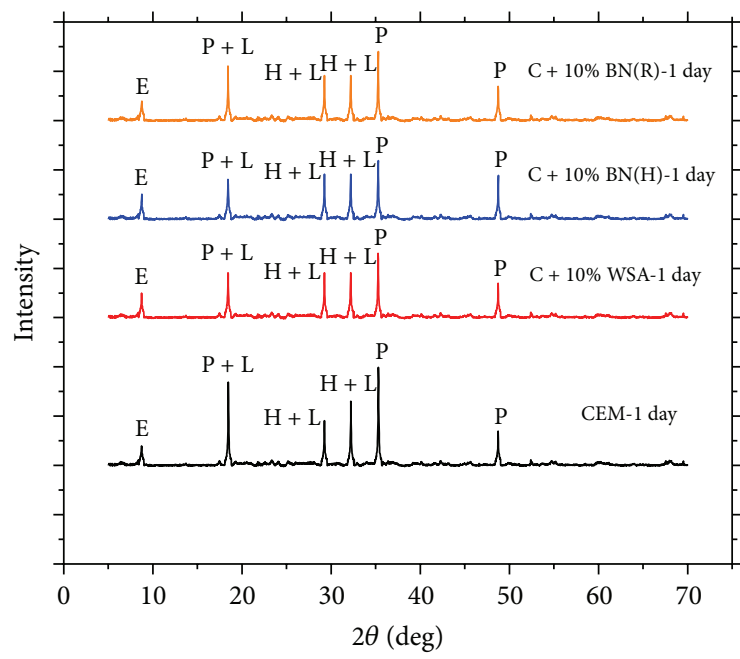

E: ettringite; $\mathrm{Ca}_{6} \mathrm{Al}_{2}\left(\mathrm{SO}_{4}\right)_{3}(\mathrm{OH})_{12} \cdot 26\left(\mathrm{H}_{2} \mathrm{O}\right)$, syn.; hexagonal $\mathrm{H}$ : hatrurite; $\mathrm{Ca}_{3} \mathrm{SiO}_{5}$, syn.; trigonal $\mathrm{L}$ : larnite; $\mathrm{Ca}_{2}\left(\mathrm{SiO}_{4}\right)$, syn.; monocline P: portlandite; $\mathrm{Ca}(\mathrm{OH})_{2}$, syn.; hexagonal

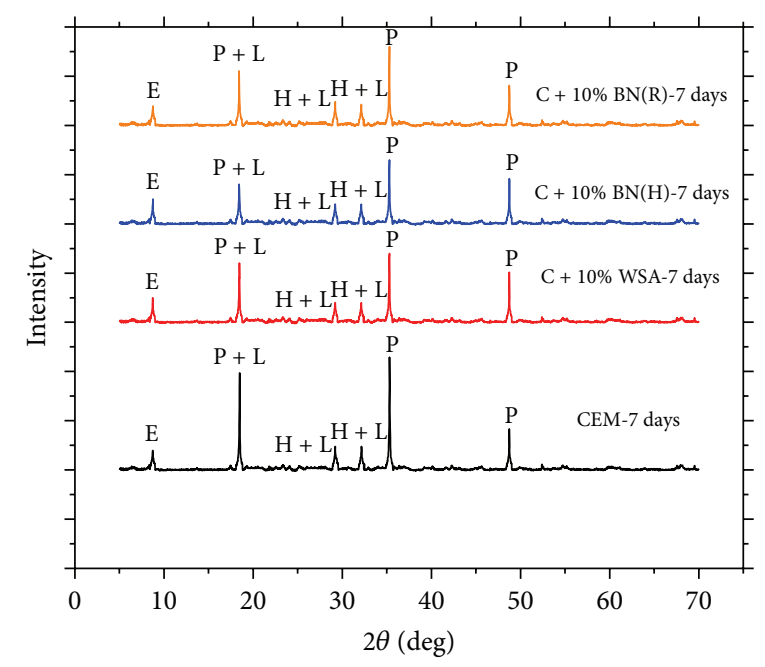

E: ettringite; $\mathrm{Ca}_{6} \mathrm{Al}_{2}\left(\mathrm{SO}_{4}\right)_{3}(\mathrm{OH})_{12} \cdot 26\left(\mathrm{H}_{2} \mathrm{O}\right)$, syn.; hexagonal $\mathrm{H}$ : hatrurite; $\mathrm{Ca}_{3} \mathrm{SiO}_{5}$, syn.; trigonal

L: larnite; $\mathrm{Ca}_{2}\left(\mathrm{SiO}_{4}\right)$, syn.; monocline

P: portlandite; $\mathrm{Ca}(\mathrm{OH})_{2}$, syn.; hexagonal

(a)

(b)

FIGURE 9: XRD of SCP formulations at (a) 1 day (b) 7 days.

TABLE 3: Variation in oxide composition of SCP formulations at 1 and 7 days.

\begin{tabular}{lcccccccc}
\hline \multirow{2}{*}{ Oxides } & \multicolumn{2}{c}{ CEM } & \multicolumn{2}{c}{$\mathrm{C}+10 \%$ WSA } & \multicolumn{2}{c}{$\mathrm{C}+10 \% \mathrm{BN}(\mathrm{H})$} & \multicolumn{2}{c}{$\mathrm{C}+10 \% \mathrm{BN}(\mathrm{R})$} \\
& 1 day & 7 days & 1 day & 7 days & 1 day & 7 days & 1 day \\
\hline $\mathrm{CaO}$ & 55.84 & 59.35 & 58.32 & 49.59 & 54.29 & 48.06 & 55.24 \\
$\mathrm{SiO}_{2}$ & 23.16 & 8.78 & 25.32 & 8.87 & 29.24 & 9.50 & 25.24 \\
$\mathrm{SO}_{3}$ & 7.34 & 17.44 & 6.75 & 23.30 & 8.49 & 19.75 & 7.49 & 9.80 \\
$\mathrm{Al}_{2} \mathrm{O}_{3}$ & 7.92 & 13.43 & 7.29 & 14.12 & 7.59 & 15.25 & 6.83 \\
$\mathrm{Fe}_{2} \mathrm{O}_{3}$ & 1.28 & 3.57 & 4.52 & 1.59 & 2.80 & 1.55 & 4.40 \\
$\mathrm{~K}_{2} \mathrm{O}$ & 1.20 & 1.06 & 0.68 & 0.71 & 1.32 & 1.22 & 1.08 \\
$\mathrm{MgO}$ & 2.48 & 0.40 & 1.19 & 0.56 & 1.29 & 0.52 & 1.69 \\
\hline
\end{tabular}

TABLE 4: Pore sizes and total porosity of SCP formulations at 1 and 7 days.

\begin{tabular}{|c|c|c|c|c|c|c|c|c|c|c|}
\hline \multirow[t]{2}{*}{ Sample ID } & \multicolumn{2}{|c|}{ Avg. pore radius (nm) } & \multicolumn{2}{|c|}{ Max. pore radius $(\mathrm{nm})$} & \multicolumn{2}{|c|}{ Total porosity (\%) } & \multicolumn{2}{|c|}{$\begin{array}{c}\text { Porosity (\%) } \\
(\text { diameter } \leq 100 \mathrm{~nm})\end{array}$} & \multicolumn{2}{|c|}{$\begin{array}{c}\text { Porosity }(\%) \\
(\text { diameter } \geq 100 \mathrm{~nm})\end{array}$} \\
\hline & $1 \mathrm{~d}^{*}$ & $7 \mathrm{~d}$ & $1 \mathrm{~d}$ & $7 \mathrm{~d}$ & $1 \mathrm{~d}$ & $7 \mathrm{~d}$ & $1 \mathrm{~d}$ & $7 \mathrm{~d}$ & $1 \mathrm{~d}$ & $7 \mathrm{~d}$ \\
\hline CEM & 18.5 & 10.2 & 56728.5 & 57355.7 & 15.3 & 16.6 & 45.4 & 68.2 & 54.6 & 31.8 \\
\hline $\mathrm{C}+10 \% \mathrm{WSA}$ & 19.4 & 5.7 & 57011.4 & 52945.6 & 17.5 & 12.5 & 43.7 & 84.5 & 56.3 & 15.5 \\
\hline $\mathrm{C}+10 \% \mathrm{BN}(\mathrm{R})$ & 20.2 & 7.1 & 55572.5 & 56169.2 & 20.1 & 13.5 & 44.3 & 81.3 & 55.7 & 18.7 \\
\hline $\mathrm{C}+10 \% \mathrm{BN}(\mathrm{H})$ & 19.7 & 6.5 & 55653.4 & 54521.6 & 18.4 & 12.6 & 42.9 & 78.4 & 57.1 & 21.6 \\
\hline
\end{tabular}

* "d" denotes number of days.

1 and 7 days. The XRD patterns of hydrated cement paste prepared with and without SRM are shown in Figure 9. The reduction in the diffraction peaks of calcium hydroxide in WSA and heated bentonite SCP formulations indicates the efficiency of these materials as pozzolan. The reduction of calcium hydroxide in these mixes is also responsible for improved compressive and flexural strength and better resistance against water absorption and acid attack. In addition, all SCP formulations showed the presence of ettringite
$\left[\mathrm{Ca}_{6} \mathrm{Al}_{2}\left(\mathrm{SO}_{4}\right)_{3}(\mathrm{OH})_{12} \cdot 26\left(\mathrm{H}_{2} \mathrm{O}\right)\right]$, hatrurite $\left[\mathrm{Ca}_{3} \mathrm{SiO}_{5}\right]$, and larnite $\left[\mathrm{Ca}_{2}\left(\mathrm{SiO}_{4}\right)\right]$ at 1 and 7 days.

\section{Conclusions and Recommendations}

This research work evaluated the effect of WSA and bentonite (raw and heated) on the overall response of SCP formulations. The characterization of SRMs is essential as they affect water demand, superplasticizer demand, flow behavior, strength, 
durability, microstructure, and mineralogy of SCP formulations. Based on experimental investigations, the following conclusions can be drawn.

(i) Bentonite and WSA SCP formulations showed higher water and superplasticizer demands. For bentonite, the increase in demand is due to larger surface area arising from smaller particle size and layered structure while for WSA the increase is due to particle shape, texture, and larger surface area. In addition, due to individual characteristics of each SRM, the SCP formulations showed increase in flow time indicating high friction offered during flow.

(ii) The pozzolanic SCP formulations showed better performance than reference SCP formulation due to reaction of these pozzolans with free lime, which enhances the mechanical and durability performance by reducing free lime content.

(iii) Among all SCP formulations, WSA formulation showed the best mechanical and durability performance due to better free lime consuming ability and reduced porosity of the system. Moreover, in comparison to raw bentonite, heat treated bentonite at $150^{\circ} \mathrm{C}$ improved the mechanical and durability performance of SCP formulations.

(iv) The utilization of WSA and bentonite in SCP formulations provides cost effective, durable, and environmental friendly option to construction industry.

It is suggested that further research should be carried out to evaluate the long-term performance of these SRMs with different replacement levels in self-compacting paste system. The long-term performance includes strength, durability, microstructural, and mineralogical analyses. In addition, detailed studies should be carried out on self-compacting mortar and concrete prepared with these SRMs.

\section{Abbreviations}

$\mathrm{BN}$ : Bentonite

CEM: Reference self-compacting paste formulation

EDX: Energy dispersive X-ray spectroscopy

LSP: Lime stone powder

MK: Metakaolin

MIP: Mercury intrusion porosimetry

OPC: Ordinary Portland Cement

SCP: Self-compacting paste

SCM: Self-compacting mortar

SCC: Self-consolidating concrete

SAI: Strength activity index

SEM: Scanning electron microscopy

SRMs: Secondary raw materials

WSA: Wheat straw ash

XRD: X-ray diffraction.

\section{Conflict of Interests}

The authors declare that there is no conflict of interests regarding the publication of this paper.

\section{Acknowledgments}

The authors are very grateful to Laboratory Staff of NUST Institute of Civil Engineering, National University of Sciences and Technology, Pakistan, for their support in synthesis of WSA and grinding of bentonite. The first author would also like to acknowledge Higher Education Commission (HEC), Pakistan, for providing the study grant.

\section{References}

[1] V. B. Bosiljkov, "SCC mixes with poorly graded aggregate and high volume of limestone filler," Cement and Concrete Research, vol. 33, no. 9, pp. 1279-1286, 2003.

[2] A. Yahia, M. Tanimura, and Y. Shimoyama, "Rheological properties of highly flowable mortar containing limestone fillereffect of powder content and W/C ratio," Cement and Concrete Research, vol. 35, no. 3, pp. 532-539, 2005.

[3] B. Felekoğlu, K. Tosun, B. Baradan, A. Altun, and B. Uyulgan, "The effect of fly ash and limestone fillers on the viscosity and compressive strength of self-compacting repair mortars," Cement and Concrete Research, vol. 36, no. 9, pp. 1719-1726, 2006.

[4] A. A. A. Hassan, M. Lachemi, and K. M. A. Hossain, "Effect of metakaolin and silica fume on the durability of selfconsolidating concrete," Cement and Concrete Composites, vol. 34, no. 6, pp. 801-807, 2012.

[5] K. A. Melo and A. M. P. Carneiro, "Effect of Metakaolin's finesses and content in self-consolidating concrete," Construction and Building Materials, vol. 24, no. 8, pp. 1529-1535, 2010.

[6] M. Safiuddin, J. S. West, and K. A. Soudki, "Properties of freshly mixed self-consolidating concretes incorporating rice husk ash as a supplementary cementing material," Construction and Building Materials, vol. 30, pp. 833-842, 2012.

[7] T. Akram, S. A. Memon, and H. Obaid, "Production of low cost self compacting concrete using bagasse ash," Construction and Building Materials, vol. 23, no. 2, pp. 703-712, 2009.

[8] S. A. Rizwan and T. A. Bier, "Blends of limestone powder and fly-ash enhance the response of self-compacting mortars," Construction and Building Materials, vol. 27, no. 1, pp. 398-403, 2012.

[9] J. Mirza, M. Riaz, A. Naseer, F. Rehman, A. N. Khan, and Q. Ali, "Pakistani bentonite in mortars and concrete as low cost construction material," Applied Clay Science, vol. 45, no. 4, pp. 220-226, 2009.

[10] S. A. Memon, R. Arsalan, S. Khan, and T. Y. Lo, "Utilization of Pakistani bentonite as partial replacement of cement in concrete," Construction and Building Materials, vol. 30, pp. 237242, 2012.

[11] H. Biricik, F. Aköz, I. Berktay, and A. N. Tulgar, "Study of pozzolanic properties of wheat straw ash," Cement and Concrete Research, vol. 29, no. 5, pp. 637-643, 1999.

[12] P. Lawrence, M. Cyr, and E. Ringot, "Mineral admixtures in mortars," Cement and Concrete Research, vol. 33, pp. 1939-1947, 2003.

[13] Y. Zhang, A. E. Ghaly, and B. Li, "Physical properties of wheat straw varieties cultivated under different climatic and soil conditions in three continents," American Journal of Engineering and Applied Sciences, vol. 5, no. 2, pp. 98-106, 2012.

[14] USDA, World Wheat Supply and Disappearance, United States Department of Agriculture, 2014, http://www.ers.usda.gov/ data-products/wheat-data.aspx\#.U-OkUBEf38O. 
[15] X. Pan and Y. Sano, "Fractionation of wheat straw by atmospheric acetic acid process," Bioresource Technology, vol. 96, no. 11, pp. 1256-1263, 2005.

[16] B. Shrivastava, P. Nandal, A. Sharma et al., "Solid state bioconversion of wheat straw into digestible and nutritive ruminant feed by Ganoderma sp. rckk02," Bioresource Technology, vol. 107, pp. 347-351, 2012.

[17] S. Hedjazi, O. Kordsachia, R. Patt, A. J. Latibari, and U. Tschirner, "Alkaline sulfite-anthraquinone (AS/AQ) pulping of wheat straw and totally chlorine free (TCF) bleaching of pulps," Industrial Crops and Products, vol. 29, no. 1, pp. 27-36, 2009.

[18] H. Chen, F. Wang, C. Zhang, Y. Shi, G. Jin, and S. Yuan, "Preparation of nano-silica materials: the concept from wheat straw," Journal of Non-Crystalline Solids, vol. 356, no. 50-51, pp. 2781-2785, 2010.

[19] F. Talebnia, D. Karakashev, and I. Angelidaki, "Production of bioethanol from wheat straw: an overview on pretreatment, hydrolysis and fermentation," Bioresource Technology, vol. 101, no. 13, pp. 4744-4753, 2010.

[20] L. Xie, M. Liu, B. Ni, X. Zhang, and Y. Wang, "Slow-release nitrogen and boron fertilizer from a functional superabsorbent formulation based on wheat straw and attapulgite," Chemical Engineering Journal, vol. 167, no. 1, pp. 342-348, 2011.

[21] T. J. Brown, T. Bide, S. D. Hannis et al., World Mineral Production 2004-08, British Geological Survey, Keyworth, UK, 2010.

[22] T. J. Brown, R. A. Shaw, T. Bide, E. Petavratzi, E. R. Raycraft, and A. S. Walters, World Mineral Production 2007-11, British Geological Survey, Keyworth, UK, 2013.

[23] ASTM, Annual Book of ASTM Standards Cement, Lime, Gypsum.: Standard Specification for Portland Cement C150-04, ASTM International, West Conshohocken, Pa, USA, 2004.

[24] P. Chang and Y. Peng, "Influence of mixing techniques on properties of high performance concrete," Cement and Concrete Research, vol. 31, no. 1, pp. 87-95, 2001.

[25] S. A. Rizwan and T. A. Bier, "Self-consolidating mortars using various secondary raw materials," ACI Materials Journal, vol. 106, no. 1, pp. 25-32, 2009.

[26] ASTM, "Annual Book of ASTM Standards Cement, Lime, Gypsum., Stand. Test Method Flexural Strength Hydraul. Mortars," Tech. Rep. C348-08, ASTM International, New York, NY, USA, 2004.

[27] ASTM, "Annual Book of ASTM Standards Cement, Lime, Gypsum, Stand. Test Method Compressive Strength Hydraul. Mortars," Tech. Rep. C349-08, ASTM International, USA, 2004.

[28] ASTM, "Standard test method density, absorption, voids hardened concrete," Annual Book of ASTM Standards Concrete and Aggregates C 642-04, ASTM International, 2004.

[29] P. Rawal, Development of durable concrete from pulverized fly ash and pozzolan derived from agricultural wastes [M.S. thesis], Asian Institute of Technology, Bangkok, Thailand, 2003.

[30] P. Hewlett, Lea's Chemistry of Cement and Concrete, Elsevier, San Diego, Calif, USA, 4th edition, 1998.

[31] P. Metha and P. Monteiro, Concrete: Microstructure, Properties and Materials, McGraw-Hill, New York, NY, USA, 2006.

[32] ASTM, Annual Book of ASTM Standards Concrete and Aggregates: Standard Specification for Coal Fly Ash and Raw or Calcined Natural Pozzolan for Use in Concrete. C618-08a, ASTM International, West Conshohocken, Pa, USA, 2004.

[33] H. Biricik, F. Aköz, F. Türker, and I. Berktay, "Resistance to magnesium sulfate and sodium sulfate attack of mortars containing wheat straw ash," Cement and Concrete Research, vol. 30, no. 8, pp. 1189-1197, 2000.

[34] H. Visvesvaraya, "Recycling of agricultural wastes with special emphasis on rice husk ash," in Proceedings of the Use of Vegetable Plants and Their Fibers as Building Materials Joint Symposium, pp. 1-22, Rilem/CIB/NCCL, Baghdad, Iraq, 1986.

[35] S. Ahmad, S. A. Barbhuiya, A. Elahi, and J. Iqbal, "Effect of Pakistani bentonite on properties of mortar and concrete," Clay Minerals, vol. 46, no. 1, pp. 85-92, 2011.

[36] N. M. Al-Akhras and B. A. Abu-Alfoul, "Effect of wheat straw ash on mechanical properties of autoclaved mortar," Cement and Concrete Research, vol. 32, no. 6, pp. 859-863, 2002.

[37] F. Lange, H. Mörtel, and V. Rudert, "Dense packing of cement pastes and resulting consequences on mortar properties," Cement and Concrete Research, vol. 27, no. 10, pp. 1481-1488, 1997.

[38] V. Ramachandran, Concrete Admixtures Handbook, Properties, Science and Technology, Noyes, Saddle River, NJ, USA, 1995.

[39] A. M. Neville, "Aggregate bond and modulus of elasticity of concrete," ACI Materials Journal, vol. 94, no. 1, pp. 71-74, 1997. 

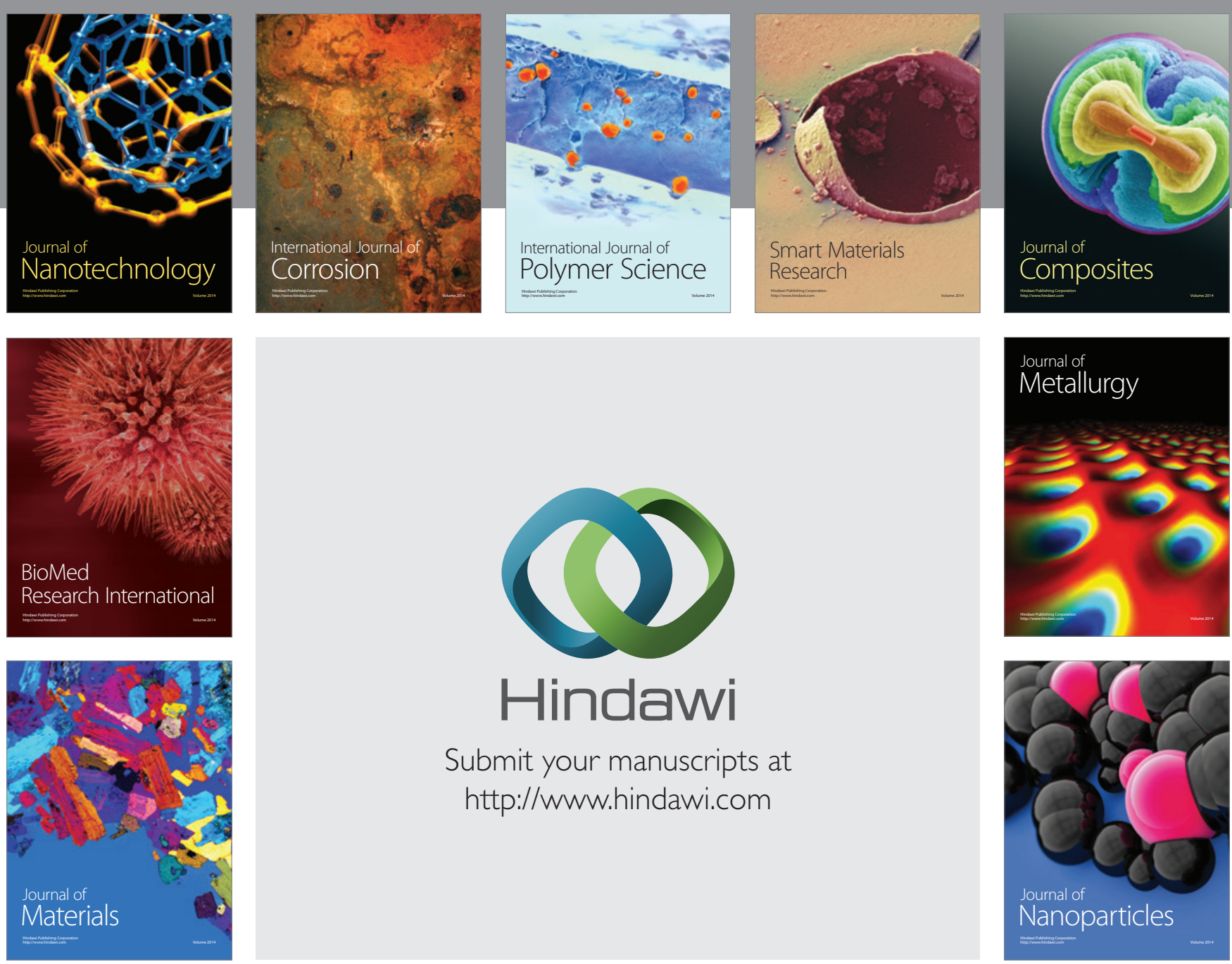

Submit your manuscripts at http://www.hindawi.com
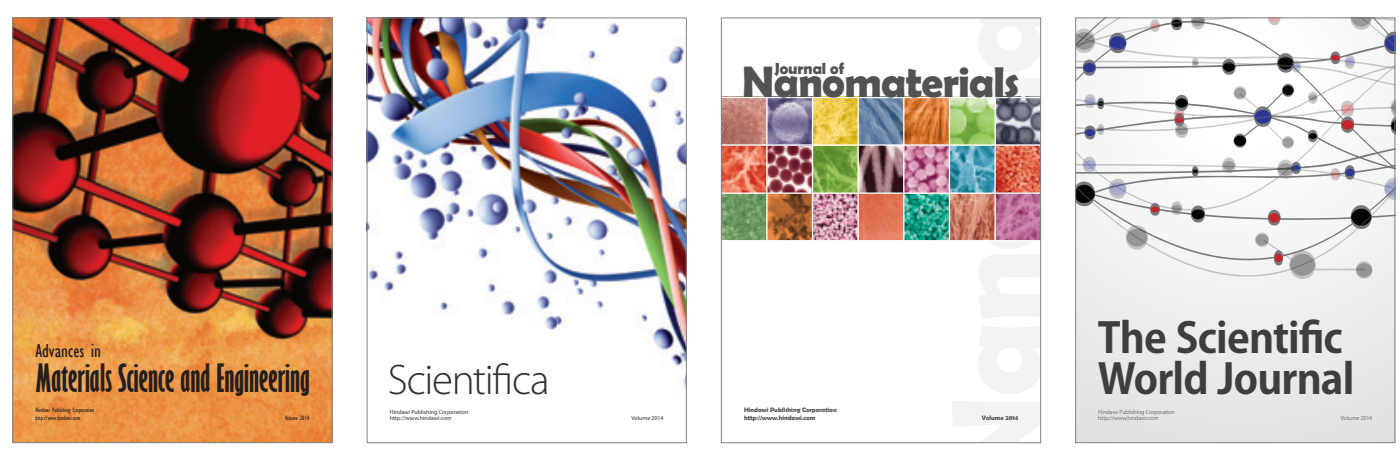

\section{The Scientific World Journal}
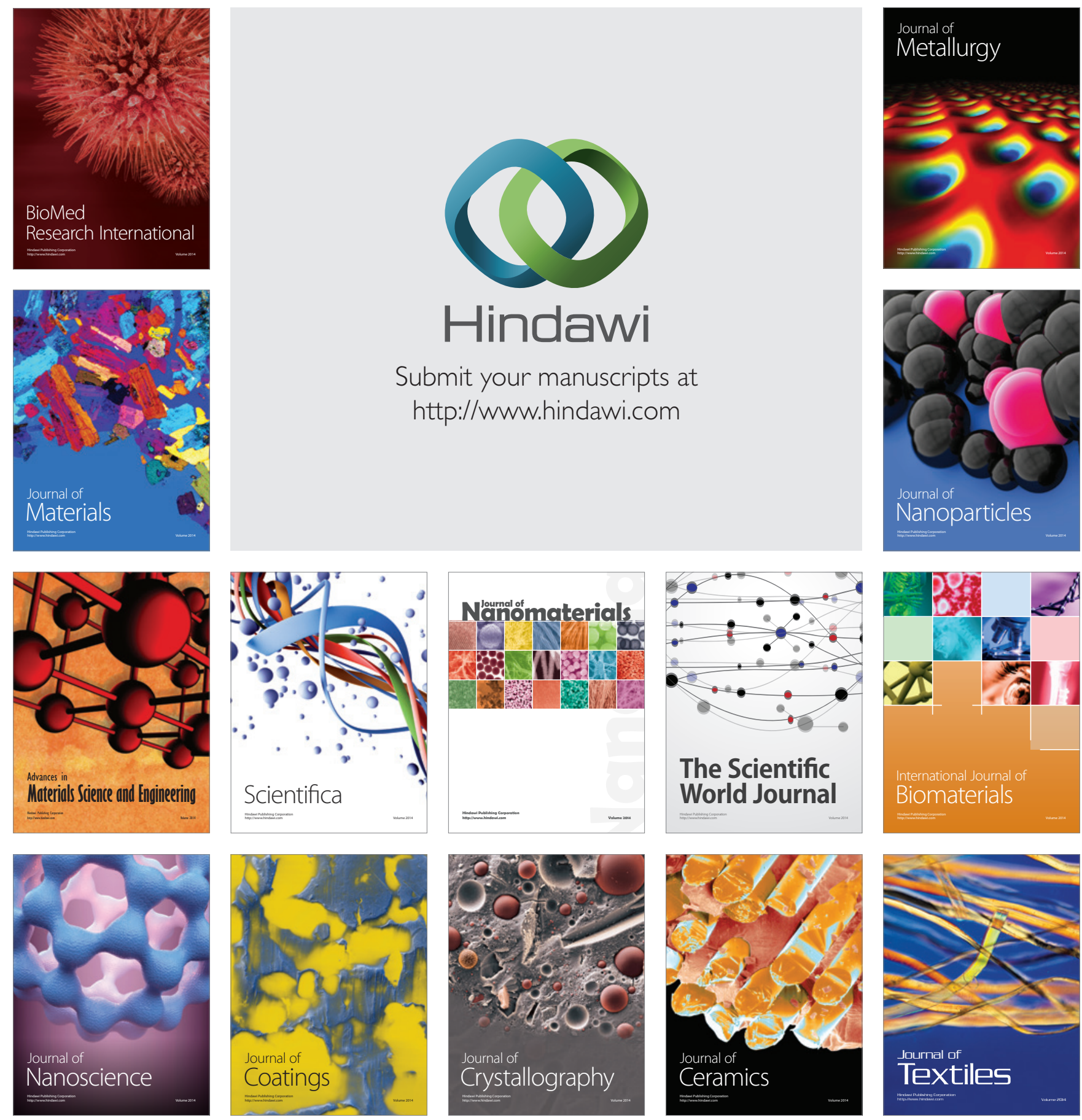